\title{
EUROPEOS Y NO EUROPEOS EN MANUALES ESCOLARES DE GEOGRAFÍA UNIVERSAL, COLOMBIA 1970-1990
}

\author{
Carmen Patricia Cerón Rengifo ${ }^{12}$ \\ Universidad de Nariño - Colombia \\ patriciac1@hotmail.com
}

Recepción: 28/02/2011

Evaluación: $25 / 05 / 2011$

Aceptación: 22/06/2011

Artículo de Reflexión

\section{RESUMEN}

Los manuales escolares de geografía expresan un discurso ideológico sobre la población, organizado bajo las operaciones intelectuales del eurocentrismo. Con el objetivo de explorar la representación de la población que se promueve como saber oficial de las ciencias sociales, se examinó una muestra de manuales escolares de geografía universal, publicados en Colombia entre 1970 y 1990, destinados a los estudiantes de octavo grado de la educación secundaria. Como pauta metodológica, se hizo un seguimiento a la representación positiva del nosotros y negativa de los otros, con herramientas proporcionadas por Van Dijk (2008). De acuerdo con Quijano (2000, 2003), se concluye que la población de Europa, Asia, África y Oceanía, se clasifica en forma jerarquizada por medio de la idea de raza, se establece una polarización semántica entre europeos y no europeos (civilizados/primitivos, modernos/tradicionales, desarrollados / subdesarrollado), y se ubica temporalmente a los no europeos, como el pasado de la trayectoría histórica que culmina en Europa.

Palabras clave: Revista Historia de la Educación Latinoamericana, enseñanza de la geografía, enseñanza secundaria, población, ciencias sociales.

\footnotetext{
${ }^{1}$ Doctora en Antropología por la Universidad Salamanca - España. Docente adscrita al Departamento de Ciencias Sociales, Universidad de Nariño. Grupos de investigación: Universidad de Nariño: Historia, Educación y Desarrollo. Grupo C de Colciencias. ${ }^{2}$ Este trabajo fue realizado como parte de los estudios en Antropología de Iberoamérica en la Universidad de Salamanca.
} 


\title{
EUROPEAN AND NON EUROPEAN IN UNIVERSAL GEOGRAPHY SCHOLAR HANDBOOKS, COLOMBIA 1970-1990
}

\author{
Carmen Patricia Cerón Rengifo \\ Universidad de Nariño - Colombia \\ patriciac1@,hotmail.com
}

\begin{abstract}
The scholar geography handbooks express an idelogical speech on population organized under the intelectual operations of the Eurocentrism. With the objective of exploring the representation of the popualtion promoted as an oficial knowledge of social studies, universal geography scholar handbooks samples were published in Colombia between 1970 and 1990; they were addressed to eighth students of highschool. As a methodological guideline, a follow -up was carried out to the positive representation of us and negative of others, the tools were taken from Van Dijk (2008). According to Quijano (2000, 2003), it is concluded that Euroean, Asian, African and Oceania population are classified into a hierarchical way by means of the race idea; it is established a semantic polarization between European and non european (civilized/ primitives, modern and traditional, developed / underdeveloped) and it is located temporarily in the non European as the past of the historical trajectory ending up in Europe.
\end{abstract}

Key words: Journal of Latin American Education History, teaching of geography, population, bigh school, social sciences. 
Europeos y no Europeos en Manuales Escolares de Geografía Universal, Colombia 1970-1990

\title{
EUROPEUS E NÃO EUROPEUS EM MANUAIS ESCOLARES DE GEOGRAFIA UNIVERSAL, COLÔMBIA 1970-1990
}

\author{
Carmen Patricia Cerón Rengifo \\ Universidade de Nariño - Colômbia \\ patriciac1@hotmail.com
}

\section{RESUMO}

Os manuais escolares de geografia expressam um discurso ideológico sobre a população, organizado sob as operações intelectuais do eurocentrismo. Com o objetivo de explorar a representação da população que se promove como saber oficial das ciências sociais, examinou-se uma mostra de manuais escolares de geografia universal, publicados na Colômbia entre 1970 e 1990, destinados aos estudantes de oitavo grau da educação secundária. Como pauta metodológica, fez-se um seguimento à representação positiva de nós e negativa dos outros, com ferramentas proporcionadas por Van Dijk (2008). De acordo com Quijano $(2000,2003)$ conclui-se que a população da Europa, Ásia e Oceania, é classificada em forma hierarquizada por meio da ideia de raça, se estabelece uma polarização semântica entre europeus e não europeus (civilizado-primitivos, moderno-tradicionais, desenvolvimentos/ subdesenvolvimentos), e se estabelece temporalmente aos não europeus, como o passado da trajetória histórica que culmina na Europa.

Palavras-chave: Revista História da Educação Latino-americana, ensino de geografia, ensino secundário, população, ciências sociais. 


\section{INTRODUCCIÓN}

Las investigaciones con manuales escolares han mostrado que la visión de lo social contenida en ellos, promueve una ideología que expresa las posiciones y relaciones sociales del orden social establecido ${ }^{3}$. En lo concerniente a la representación de los europeos en correspondencia con América, varios estudios realizados en América Latina han establecido que los europeos y su cultura se valoran positivamente en oposición a las poblaciones categorizadas como indígenas y negros ${ }^{4}$. A la vez se forjaron discursos en los cuales, los pobladores de la península ibérica se convierten en actores malvados, estrategia para legitimar la independencia ${ }^{5}$. En este escenario, son menos frecuentes las publicaciones sobre la representación de los europeos en relación con la población de los otros continentes. Entre ellos, se haya la publicación de Lo Russo quien manifiesta que las imágenes sobre africanos y asiáticos en los manuales de historia, de la educación secundaria de Argentina, manejan la idea de la superioridad racial, étnica, política y económica de Occidente con la que se legitima la acción colonialista europea, en aras de una modernización y un desarrollo valorados positivamente por la cultura occidental. En España, Morales y Lischinsky, indagando las imágenes en una muestra de libros de texto de ciencias sociales, observaron que se reproduce una representación de un

${ }^{3}$ Véase por ejemplo, CHOPPIN, Alain. (2000): "Pasado y presente de los textos escolares", en La cultura escolar de Europa. Tendencias históricas emergentes. RUÍZ, J. Madrid, Biblioteca nueva; JOHNSEN, Egil Borre. (1996): Libros de texto en el calidoscopio. Estudio crítico de la literatura y la investigación sobre los textos escolares. Barcelona, Pomares.

${ }^{4}$ Para Colombia ver: HERRERA, Martha; PINILLA, Alexis; SUAZA, Luz. (2003): La identidad nacional en los textos escolares de ciencias sociales. Colombia 1900-1950. Bogotá, Universidad Pedagógica Nacional; MENA, María Isabel. (2006): "La historia de las personas afrocolombianas a partir de las ilustraciones contenidas en los textos de ciencias sociales para la educación básica", en Enunciación. No. 11. Bogotá, Universidad Distrital; SOLER, Sandra. (2008): "Pensar la relación análisis crítico del discurso y educación. El caso de la representación de indígenas y afro descendientes en los manuales escolares de ciencias sociales en Colombia", en Discurso \& sociedad. No. 2.

5 ARREDONDO, María Adelina. (2003): "Desplazando al Rey en la escuela de la nueva nación mexicana: el Catecismo de República", en Historia de la Educación. No. 22. Universidad de Salamanca.

LO RUSSO, Cecilia Alicia. (2009): "La visión de los pueblos de Asia y África en los manuales de historia", en Didáctica de las ciencias sociales, geografía e historia. No. 61. España. MORALES, Oscar y LISCHINSKY, Alon. (2008): “Discriminación a través de las ilustraciones de libros de texto de Enseñanza Secundaria Obligatoria en España”, en Discurso \& Sociedad. No. 2. 
endogrupo, identificado como español, europeo, occidental, desarrollado, perteneciente al Primer Mundo, dotado con características tales como la armonía, la prosperidad, la equidad, la generosidad y la competencia técnica, en comparación con el exogrupo, que es el resto del mundo, representado con características negativas, con estereotipos del fenotipo no caucásico (desordenado, poco productivo, caótico), con énfasis en rasgos convencionalmente primitivos y étnicos.

En este contexto, el presente documento busca explorar el discurso construido en torno a la población de Europa, Asia, África y Oceanía, que se promovió como saber oficial en los manuales escolares de geografía universal, publicados en Colombia entre 1970 y 1990. Se mantuvo como pauta metodológica el seguimiento a la estrategia básica que se expresa en el discurso ideológico, de hacer una representación positiva de sí mismo y una representación negativa de los demás, usando las herramientas aportadas por Van Dijk. Se seleccionó una muestra de seis manuales escolares de geografía universal destinados a estudiantes de octavo grado, de la educación secundaria en Colombia. Se realizó una selección y registro de los contenidos bajo los títulos sobre población y otros asociados, en las unidades sobre Europa ${ }^{9}$, Asia, África y Oceanía.

Siguiendo a Quijano ${ }^{10}$ se sugiere que la representación de la población se organiza con base en un discurso ideológico que clasifica a la gente de acuerdo con los principios del eurocentrismo, intersubjetividad del patrón de poder del mundo moderno colonial. Para este autor, Europa fue constituida como nueva entidad - identidad histórica después y como consecuencia de América. Con el control del mercado mundial en las

${ }^{8}$ VAN DIJK, Teun. (2008): Ideología y discurso. Barcelona, Ariel.

9 De europa sólo se trabajó con los contenidos que aludían a la relación de Europa con los demás continentes, dejando de lado, la clasificación interna de la población, que fue trabajada en otro documento: CERÓN, Patricia. (2011): Europas: Representación de la población en manuales escolares de geografía universal, Colombia (1970-1990), en Influencias Inglesas en la Educación Española e Iberoamericana (1810-2010). Congreso Internacional Iberoamericano, V Conversaciones Pedagógicas de Salamanca. Salamanca 2011.

QUIJANO, Aníbal. (2000): “Colonialidad y Clasificación Social”, en Journal of World Systems Research. No. 6 (2). Special Issue. Festschrift For Immanuel Wallerstein - Part 1; QUIJANO, Aníbal (2003): “Colonialidad del poder, eurocentrismo y América Latina", en La colonialidad del saber: eurocentrismo y ciencias sociales. Perspectivas latinoamericanas. E. Lander (Comp.). Buenos Aires, Clacso. 
zonas del Atlántico, se produce el desplazamiento de la hegemonía desde las costas del Mediterráneo, y luego desde las costas ibéricas hacia el Atlántico noroccidental. En este proceso, Europa u Occidente (Europa Occidental después), se erige como nueva identidad geocultural. Ya como centro del capitalismo mundial, impone el dominio colonial sobre todos los territorios y organizaciones políticas de base territorial del planeta, conformando el sistema mundo. Las regiones y las poblaciones fueron clasificadas con el patrón eurocentrado que les asignó nuevas identidades geoculturales, así, fueron establecidas África, Asia y después Oceanía.

La población se codificó con base en la idea de raza como naturalización de las relaciones coloniales de dominación entre europeos y no europeos. La idea de raza se convirtió en el criterio primordial para distribuir a la población en los rangos, lugares y roles de la estructura de poder en el nuevo orden social. En el mismo camino de expansión mundial del dominio colonial, Europa concentró las formas de control de la subjetividad, de la cultura y del conocimiento. En el eurocentrismo se fue afirmando una perspectiva de la historia que ubicó a los pueblos colonizados, a sus historias y culturas, como el pasado de una trayectoria que culmina en Europa. Los pueblos colonizados fueron posicionados como razas inferiores, por lo tanto, como primitivos, anteriores a los europeos.

La modernidad y la racionalidad se pensaron como experiencias y productos exclusivamente europeos. Las relaciones intersubjetivas y culturales entre Europa, específicamente Europa Occidental, y el resto del mundo, se organizaron en una concepción de humanidad según la cual, la población del planeta se diferenciaba en categorías que se corresponden con las diferencias de poder entre europeos y noeuropeos: Europa civilizada, científica, racional, moderna. No Europa primitiva, mágica, irracional, tradicional. Los europeos difundieron y establecieron esta perspectiva histórica como hegemónica dentro de la nueva intersubjetividad del patrón mundial de poder ${ }^{11}$.

${ }^{11}$ QUIJANO. (2003): óp., cit, p. 67. 
Europeos y no Europeos en Manuales Escolares de Geografía Universal, Colombia 1970-1990

\section{La población en manuales escolares de geografía universal, Colombia (1970-1990)}

\section{Europa}

Dando continuidad al esquema clasificatorio de la colonialidad que emerge con el mundo moderno colonial, en los manuales escolares la población del llamado Viejo Continente se clasifica con base en la idea de raza. Europa se identifica con la raza blanca, Asia con la raza amarilla y África con la raza negra, estableciendo el orden de jerarquía racial, cultural y geográfico: Europa/ Asia /África. En este nivel de organización socio espacial se utiliza la categoría geográfica (Europa, Asia, África), que metonímicamente sustituye a los europeos, asiáticos y africanos.

El discurso se enuncia desde la perspectiva de los europeos. El nosotros está constituido por la categoría blanco de Europa. Los otros en este nivel socio espacial, son Asia y África. El nosotros se evidencia a través de una representación positiva de la categoría blanco habitante en Europa, que se asocia con características del desarrollo, la modernidad y la civilización, haciendo énfasis en los aspectos positivos, a la vez, que se quita el énfasis en los aspectos negativos, estrategia básica del discurso ideológico de identidad de los grupos sociales ${ }^{12}$.

Se hace hincapié en separar a Europa de los demás continentes de acuerdo con criterios raciales, culturales y de desarrollo. Europa desarrollada/América Latina, Asia y África subdesarrollados. El modelo demográfico de Europa, alta densidad de población y bajas tasas de natalidad y de mortalidad, se muestra como marca de los países desarrollados. Se atribuye a la antigüedad de las naciones, con una civilización a la que se le asigna más de 2000 años, es decir, ligada con el cristianismo; el clima templado, la abundancia de los recursos naturales, la alta productividad, el alto nivel de vida, los mayores ingresos, los avances médicos y la emigración. El alto crecimiento demográfico, que para los otros se considera un indicador del subdesarrollo, y la alta densidad de población, no se califican como un problema en la categoría europeos, aduciendo la emigración a otros continentes y a los grandes centros de actividad económica, así como la adecuada distribución de la población.

\footnotetext{
${ }^{12}$ VAN DIJK. (2008): óp., cit, pp. 56-58.
} 
La categoría Europa se representa con los indicadores de la modernidad, como ser vanguardia de la economía, la ciencia, la técnica y la cultura contemporánea. Y como la civilización, cuna y actualidad de la mayor civilización llamada Occidental, expresada en la modernidad. A diferencia de Asia que sería el pasado remoto de la civilización, y de África que apenas iniciaría la entrada a la cultura moderna. En otras palabras, se maneja la idea de europeos civilizados/asiáticos antiguamente civilizados/africanos no civilizados. En consecuencia, la categoría Europa se muestra como el centro del mundo que reparte la civilización por todas partes. América, Asía, África y Oceanía se presentan aisladas hasta la llegada de los conquistadores y colonizadores europeos, como acontecimiento que les permite acceder al beneficio de la civilización. En la siguiente cita, se evidencia la primacía otorgada a Europa:

\section{(...). Por ejemplo: aunque en el Antiguo Continente} existia cierta unidad física desde el punto de vista cultural, se observan tres unidades diferentes: Europa, de raza blanca, cuna de la civilización occidental; Asia, de raza amarilla, asiento de las civilizaciones milenarias como la china y la hindú, aislada durante muchos siglos, y África, de raza negra, donde floreció la cultura egipcia, pero que, como la anterior, permaneció aislada y casi desconocida hasta el siglo pasado, cuando países europeos vieron en ella la posibilidad de conquistarla y convertirla en dominio colonial ${ }^{3}$.

Para explicar el mayor nivel de vida y la civilización europea, se usan dos argumentos: en primer lugar, se retrocede en la historia para identificar los antecedentes de los logros del presente. Se recrea el mito según el cual, Europa es la cuna de la civilización occidental, continuidad lineal progresiva que se inicia con los indoeuropeos, para luego pasar a los griegos, los romanos y los cristianos, cada cual aportando un legado que se acumula como bien para el presente. Los indoeuropeos heredarían la creatividad y el espíritu artístico. Grecia la democracia y la filosofía, la ciencia, las letras, la arquitectura, la escultura. Roma el latín y la ciencia

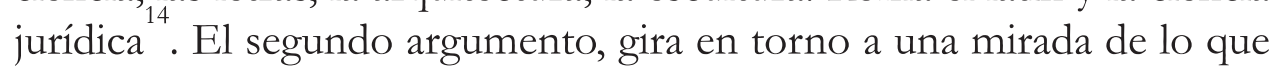
es y tiene Europa, como productora autónoma de sí misma, obviando

\footnotetext{
${ }^{13}$ MARAÑÓN, Mortiner; GÓMEZ, Hilda; VEGA, Alcira; LÓPEZ, Gilma; PRADA Cora. (1984): Geografía Universal 3. Bogotá, Norma, p. 12.

${ }^{14}$ Cfr. ARBELÁEZ, Federico. (1976): Geografía universal 3: Asia, Europa, África, Oceanía, Regiones polares. Bogotá, Norma, p. 105.
} 
o mencionando poco las relaciones de dominación, explotación y conflicto con el resto de la población, tales como la ubicación en la zona templada del norte del globo terráqueo con clima templado, la geomorfología de las costas que posibilitan los puertos, la alta cantidad de población, la civilización previa, el desarrollo de la ciencia y la técnica, la economía, la industrialización, la abundancia de recursos naturales y minerales, las fuentes energéticas, la red de comunicaciones terrestres, fluviales y aéreas, la fertilidad de sus suelos y su gente. Parra aduce que la población es propicia para la civilización por el hecho de estar ubicada en la zona templada, donde las estaciones producirían un hombre particular, con métodos de vida, ritmo y orden "lo que ha hecho del hombre europeo el elemento humano más propicio para el desarrollo de la civilización". Además, se menciona que el europeo modifica la naturaleza transformándola a su modo de vida en áreas culturales, mientras que la población de los otros continentes somete sus modos de vida y de economía a la naturaleza:

Quizá sea Europa el continente donde más desarrollo baya tenido la civilización y la técnica. La casi totalidad de su suelo ha sido utilizado y explotado mediante diversos procedimientos casi todos avanzados, es donde en mayor grado el paisaje natural ha sido modificado por el hombre y donde se creó y de donde se expandió lo que se conoce como la cultura occidental ${ }^{6}$.

En resumen, los manuales escolares expresan la ideología del eurocentrismo, en la cual Europa es el centro del desarrollo, la civilización y la modernidad, lo que se explica bajo el argumento que se debe a un proceso interno independiente, a su herencia histórica, a su población, a sus recursos naturales, a su ubicación geográfica y a su clima templado, mientras se ocultan o disminuyen los aspectos negativos sobre las formas de dominación, explotación y conflicto con las otras poblaciones, por el control de los ámbitos de la existencia en el mundo moderno colonial.

\footnotetext{
${ }^{15}$ PARRA, Juan. (1978): Geografía Universal, 3 curso de enseñanza media. Medellín, Bedout, p. 20.

CAMACHO, Mariela; MEJÍA, Bolívar; MENDOZA, Humberto. (1975): Geografía 3. Bogotá, Voluntad, p. 5.
} 


\section{Asia}

La representación de la categoría Asia en primer lugar, se organiza como alteridad de Europa. Se dibuja como una civilización antigua, aislada y estancada que precisa ser civilizada por los europeos; una sociedad inacabada y atrasada que convive con los problemas del subdesarrollo. En segundo lugar, se hace una subdivisión de la población en regiones que tiene en cuenta la ubicación según puntos cardinales: Asia Septentrional, Asia Suroriental, Asia Occidental o Medio Oriente, Asia Insular (del norte y del sur), en la cual, la población se presenta con diferentes estilos de vida la mayoría, por fuera de la modernidad, en el subdesarrollo y con inestabilidad política, excepto el caso de unos pocos países.

Asiáticos: La representación de la población del continente asiático en los manuales escolares examinados, se organiza con la codificación de la idea de raza a la que también se menciona como grupo étnico. La población es nombrada con la categoría genérica asiáticos y se muestra siendo parte de las tres razas: amarilla, blanca y negra. La primera aparece predominando en cantidad. La categoría blanco de Asia no se sitúa en un mayor nivel de jerarquía frente a la categoría amarillo y negro, dado que el discurso racista no se define sólo a partir de rasgos biológicos como tal, sino mediante el eje básico que es el diferencial de poder en la sociedad, de forma que el esquema clasificatorio no es tan fijo, se puede utilizar o hacer énfasis en cualquier variable biológica, cultural o geográfica, dependiendo del contexto específico donde el uso de una u otra variable o la combinación entre ellas, cobre sentido en el campo de poder simbólico. En tal caso, la jerarquía se organiza como: blanco europeo/ blanco, amarillo, negro de Asia.

La categoría Asia se define en relación con la categoría Europa. La imagen que se proyecta de Asia es la de ser un continente donde nacieron las grandes civilizaciones antiguas, que pasaron a Europa modificando a los pueblos primitivos, para después permanecer aislado y estancado hasta la intervención de los europeos, que posibilitaría el contacto a su interior y con la civilización occidental. Se hace una representación negativa de la población mediante criterios relacionados con el subdesarrollo como la alta densidad de población irregularmente distribuida, la pobreza y el hambre. Condiciones que se conciben como consecuencia de factores internos propios, por el mal aprovechamiento de los recursos naturales, la desigualdad en la distribución de los recursos, 
el desequilibrio entre la economía y el crecimiento de población. Se destacan los problemas en la representación, se mencionan las epidemias, la insuficiente producción de alimentos para la cantidad de gente, los daños en cultivos por los cambios estacionales (imagen del poco control de la naturaleza), incluso, se enumeran como problemas particulares aquellos que pueden vivir cualquier población del mundo como los $_{17}$ temblores, las erupciones volcánicas y el ataque de animales silvestres ${ }^{17}$.

La categoría Asia también es situada en la alteridad al asignarle contenido con las señas que se oponen a la modernidad: la costumbre, la tradición y la religión. La tradición es ligada a lo arcaico, al pasado, se concibe como un repliegue frente al dominio europeo que provoca el estancamiento económico. En cuanto a la religión, se concibe como el continente donde nacieron las religiones más difundidas en el mundo y se atribuye una gran religiosidad a su población. La religión, en oposición a la modernidad, se ve articulando la mayor parte de la vida de la gente.

En resumen, la población de Asia se dibuja como cuna de una civilización antigua (que pasó a Europa) estancada y aislada hasta que los europeos llegaron a civilizarla. Una sociedad no moderna que mantiene arraigada la religión, la costumbre y la tradición, con una gran cantidad de población, con predominio de la raza amarilla, asociada con los problemas, que vive en el subdesarrollo.

Los estilos de vida en Asia: Asia es subdivida en regiones que tienen en cuenta una organización en puntos cardinales, si bien los límites de cada región varían en los manuales escolares de geografía. Las regiones más nombradas son: Asia Septentrional, Asia Occidental, Asia Oriental y Asia Insular. No hay jerarquización entre las regiones, las diferencias en la representación se hacen de acuerdo con los estilos de vida. En la cima de la jerarquía, se ubica a los pocos países que se consideran los más desarrollados de Asia: Israel/Japón/Rusia. Israel es el mejor valorado, Japón se muestra como un país industrializado gracias a Europa y Norteamérica, a la vez que tradicional en las costumbres. Rusia, si bien se vincula con características del desarrollo se representa con atributos negativos por el comunismo. El resto de la población se relaciona con una sociedad no moderna, no civilizada y subdesarrollada, dentro de la cual, hay un nivel de jerarquía que opone sedentarismo / nomadismo, urbano/ rural, en vías de civilización/salvajes, primitivos.

\footnotetext{
${ }^{17}$ Cfr. ARBELÁEZ. (1976): óp., cit, p. 19.
} 
Asia Septentrional hace referencia a Rusia Asiática. La población es caracterizada por la baja densidad de población y una gran diversidad étnica. La gente se clasifica de acuerdo con sus estilos de vida en dos categorías: colonos/indígenas. La categoría colonos se representa mejor en comparación con la categoría indígena, siguiendo la concepción según la cual, la migración de unos humanos considerados superiores al territorio de otros señalados como inferiores se valora positivamente alegando que llevan el progreso o la civilización, mientras que una migración en dirección contraria (como Sur - Norte) se concibe como problema. En este caso, los colonos se identifican con las señas del avance económico (campos agrícolas, ferrocarril, centros industriales), al lado de los aspectos negativos del comunismo (la persecución política, el afán de libertad, la deportación), que de todas maneras le da predominio en la clasificación a su gente y a su modo de vida frente a la categoría indígena. La población categorizada como indígena se nombra como indígenas, pueblos primitivos o pueblos siberianos. Se representa utilizando el mecanismo de folklorizar la diversidad cultural y definirla con términos generales como el de tradición popular. Su estilo de vida se considera primitivo, su religión se devalúa llamándola pagana, que además, estaría condenada a no civilizarse por el tipo de expansión rusa que no permite las misiones. Parra ${ }^{18}$ describe su cultura expresando la distancia con el nosotros a través de destacar las diferencias en la organización política (aún subsiste la organización tribal), social (matrimonio por rescate), religiosa (Los grupos primitivos de la Siberia son paganos. Su religión se basa en el Tótem) y en el vestido (se compone de túnicas). Se tiene entonces que la jerarquización de la población mediante las categorías colonos e indígenas, inferioriza a la segunda categoría a través de subrayar la diferencia cultural y calificarle como primitivo, es decir perteneciente a los primeros tiempos, al pasado.

Asia Occidental o Medio Oriente se dibuja poblada por diferentes grupos pertenecientes a la raza blanca. En general, la población se clasifica en dos categorías: los árabes e Israel. La población árabe se asimila a una vida difícil caracterizada por el hambre, la escasez de recursos, la vida frugal y la escasez de comodidades. Los servicios sociales se califican con las marcas del subdesarrollo como insuficiencias en educación, salud, vivienda y alimentación, si bien se expresa que por el petróleo se ha posibilitado algunos avances.

${ }^{18}$ PARRA. (1978): óp., cit, p. 184. 
La gente se describe en términos de poca cantidad de población y con una vida alrededor de la religión y el desierto, se la vincula con rasgos estereotipados como ser guerrera, aficionada a los placeres y profundamente religiosa, cuya vida gira en torno a Mahoma. Los grupos nómadas se asocian con el referente de la tradición que perdura, que no cambia. A veces se muestran en términos de adaptación al medio ambiente como el nomadismo, el uso del camello y la vestimenta que se ajustan a las condiciones desérticas del territorio. Se pone de relieve la importancia de la religión, dando peso a un criterio que define a la sociedad no moderna. La producción en arte, arquitectura, ingeniería, escultura, cerámica y tejidos se relaciona con la religión. La religión se califica como un problema, Camacho y otros plantean que los problemas económicos y sociales son "creados por el choque entre una civilización islámica antigua, conservada hasta la actualidad con una civilización moderna que la cerca por todas partes"; a diferencia del catolicismo que se presenta como un aporte de la cultura dominante, la religión islámica se muestra como una imposición por la fuerza; los conflictos se articulan a la religión en territorios árabes, con lo cual, la región se percibe como inestable políticamente por razones internas. Israel es mejor representado, su población se muestra con un mejor nivel de vida y desarrollo en comparación a sus vecinos. En la siguiente cita, obsérvese que la información está sesgada a favor de Israel, se afirma que la política árabe con respecto a Israel es la causante de la relación conflictiva, no se dice lo mismo de Israel o se involucra a ambos agentes. Además, se justifica la intervención de las potencias como una respuesta ante la agresión, que generan exclusivamente los árabes:

La politica de los árabes con respecto a Israel es causa de permanentes conflictos que perturban la paz en el Cercano y Medio Oriente y, por consiguiente, la paz universal. Las grandes potencias intervienen cada vez que bay roces de esta indole perturbadora.

Asia Oriental comprende China, Indochina, Mongolia y Asia Meridional, llamada Asia Monzónica. La región se describe en términos del subdesarrollo, haciendo énfasis en el bajo nivel de vida, la pobreza y la miseria de la población y con los criterios del modelo demográfico

${ }_{20}^{19}$ CAMACHO y otros. (1975): óp., cit, p. 35.
ARBELÁEZ. (1976 óp., cit, p. 44. 
asociado: alta densidad de población con altas tasa de natalidad y de mortalidad. Se destaca el crecimiento demográfico como un grave problema en el cual la población aparece como responsable principal por la religión, las costumbres, la tradición, la ignorancia, el apego a la gran familia y la ineficiencia de las instituciones. Las causas de los problemas sociales se atribuyen a la religión, a la prevalencia del asentamiento rural que no permitiría la industrialización, y al crecimiento demográfico, el cual se relaciona con la miseria, el desempleo, el subempleo, la desnutrición, la escasez de alimentos, el hambre, el analfabetismo y la emigración.

En oposición a la razón como norma de la modernidad de Europa, la región se vincula con la tradición del pasado y la religión. La población se identifica con una cultura milenaria y el arraigo de la tradición, expresada en la gran cantidad de monasterios, templos y las reliquias antiguas. En cuanto a la religión, se la vincula con una gran cantidad de religiones (budismo, confucianismo, hinduismo, catolicismo, cultos animistas), ligadas a la vida cotidiana que no permitirían el desarrollo económico y la comprensión de lo social. La división en castas y muchas de las prácticas con la fauna son explicadas por el carácter religioso de la gente. Marañón y otros ${ }^{21}$ manifiestan que "las creencias religiosas están muy ligadas a la vida diaria, hasta el punto de llegar a ser un obstáculo para el desarrollo económico y el entendimiento social". A la religión se le atribuye la desigualdad social y la causa de los conflictos entre los países, silenciando las historias del poder tanto al interior de estas sociedades como en la relación con los europeos en la configuración del mundo moderno colonial. Así, De Moreno y Ortiz expresan que "El mosaico de religiones ha sido una de las causas para que en la región existan tantos conflictos entre los países; la mayoría de aquellos entre la India y Pakistán por ejemplo se debe a la religión". Se explica que la población no hace parte de la modernidad, a pesar del contacto con los europeos, quienes han construido las ciudades y los centros industriales, puesto que prevalecen los principios de la sociedad y porque no se han consolidado los Estados nacionales (marca de la modernidad), lo que conlleva a la poca unidad nacional dada la gran diversidad cultural, expresada en muchas religiones, lenguas, organizaciones sociales y costumbres.

\footnotetext{
${ }^{21}$ MARAÑÓN y otros. (1984): óp., cit, p. 36.

${ }^{22}$ DE MORENO, Elsa y ORTIZ, Luis. (1983): Geocosmos: octavo grado del nivel básico secundario. Medellín, Susaeta ediciones, p. 91.
} 
En cuanto a los estilos de vida, la población se jerarquiza entre aquella que está en vía de civilización como la urbanizada, seguida de los campesinos y finalmente, los pueblos llamados salvajes y primitivos. La civilización que se considera válida es la que se relaciona con la intervención de los europeos. La expansión europea se representa positivamente como civilizadora, mientras que la china y rusa se presentan negativamente como causa de los conflictos de la región que inciden en el atraso y el subdesarrollo. Se alega que el contacto con los europeos conlleva a la civilización, aparecen ciudades, las tradiciones van desapareciendo y la economía va cambiando, si bien, el arraigo en la religión no permite entrar en la modernidad. Las poblaciones campesinas con agricultura de autoconsumo se describen negativamente al ligarlas con sistemas primitivos, poca técnica, abundante mano de obra y el aislamiento. Las poblaciones étnicas son descalificadas al situarles como salvajes o semisalvajes, primitivos que viven al margen de la civilización. Se hacen descripciones que resaltan la diferencia cultural que rayan con la insinuación del desvío de la norma cultural.

En Parra ${ }^{23}$ se mencionan en detalle características sobre su modo de vida, el adorno (El birmano de Asam es casi salvaje, conserva sus arreos de guerra, con recargo de brazaletes y collares); la organización social (Los drávidas tienen la división social es castas matri o patrilíneas. Existe la poligamia y la mujer es quien elige al esposo); el vestido (lo hay desde el traje occidental hasta el cubresexo de hojarasca; su vestimenta es rústica y muy adornada, pero en el hombre se reduce al cubresexo); la vivienda (desde la del adobe hasta la de las copas de los arboles; algunos viven en las rocas, pero existe la choza común para varias familias), y los rituales funerarios (no entierran a los muertos).

Asia Insular del Norte es mejor representada en comparación con Asia Insular del Sur. Japón se considera un país superpoblado con una constitución democrática y un alto nivel técnico, científico, educativo e industrial, avances asignados a los países desarrollados. Los adelantos técnicos e industriales de Japón se atribuyen a la influencia cultural de Norteamérica y Europa, y a su raza, de la que se plantea que parece ser superior en Asia "pequeño, alegre, inteligente y el más apto de Asia para la civilización" . No obstante, la población del Japón no se concibe

\footnotetext{
${ }^{23}$ PARRA. (1978): óp., cit, pp. 63-64.

PARRA. (1978): óp., cit, pp. 10-11.
} 
como similar a la europea y norteamericana. Se establece un proceso de alteridad al atribuirle la raza amarilla, la tradición milenaria, algunos rasgos de personalidad específicos como ser alegre, festivo, delicado, ceremonioso aunque también culto, y resaltar las diferencias culturales siguiendo la estrategia de dar detalles sobre el rito del té, el vestido, la vivienda y el comedor, que demarca a los otros.

En oposición, Asia Insular del Sur es menos valorada. Se hace una jerarquización de los modos de vida, que se expresa en la descripción de pueblos en diferentes grados de civilización. El mayor nivel de civilización se ubica en las ciudades que han recibido la influencia de la expansión europea. En el grado más bajo de civilización son situados los pueblos llamados hombres primitivos, descritos como salvajes y semicivilizados, que conservan sus costumbres, como se dice en la siguiente cita:

\section{Es común encontrar en una misma isla hombres de ambas razas y algunos grupos viven aún en estado de semicivilización y otros en el más completo salvajismo. (...). A excepción de los hombres de las ciudades, que han recibido la influencia china o europea, los demás grupos conservan aún sus costumbres.}

Caracterizados por la economía de autoconsumo a pesar de contar con abundantes recursos y, por su religión, definida como magia y animismo, que se asocia con las poblaciones "más atrasadas". Se sigue la estrategia de representarlos a través de temas que destacan la diferencia cultural en comparación con la población urbana considerada ya civilizada. Parra ${ }^{26}$ realiza descripciones que mencionan características particulares en las relaciones de pareja (es el hombre quien compra a la mujer, la cual es castigada con la pena de muerte si comete adulterio), la religión (los suntuosos templos budistas o musulmanes o las pirámides escalonadas de las religiones primitivas), los ritos funerarios (Una de las cosas que caracterizan a estos pueblos es la de dejar los cadáveres descubiertos hasta su putrefacción) y el vestido (es muy reducido. Se lleva el torso descubierto y solamente se usa el cubresexo, pero los habitantes de las ciudades o los ya civilizados llevan túnicas llamadas sarongs, pantalones y turbantes, vestiduras lujosas, generalmente de seda fina).

${ }^{25}$ Ibídem., p. 93.
${ }^{26}$ Ibídem., p. 93. 
Europeos y no Europeos en Manuales Escolares de Geografía Universal, Colombia 1970-1990

En resumen, el contexto de referencia a los asiáticos en el discurso ideológico expresado en los manuales de geografía examinados es el siguiente: en el pasado fueron (ya no los son) una civilización milenaria; la civilización de Asia pasó a Europa transformando a los pueblos primitivos; en Asia la civilización se estancó y permaneció aislada hasta la llegada de los europeos; la expansión europea lleva civilización reflejada en la vida en las ciudades, a diferencia de otras expansiones que son negativas; ahora constituyen una gran cantidad de población, pobre, subdesarrollada y con inestabilidad política; su sociedad no se moderniza por la resistencia que opone la religión y la tradición.

\section{África}

La representación que se hace sobre la población de África se aborda en dos niveles de organización socio espacial. En primer lugar, como continente el significado del discurso sobre la población remite al subdesarrollo y al atraso cultural; imagen que se refuerza desde subtítulos que aparecen como: factores que han retardado el desarrollo en África, atraso y promesa de África. En segundo lugar, se hace una subdivisión de África por regiones: África Septentrional, con predominio de gente categorizada como blanca árabe y bereber; África Tropical con mayoría de población enmarcada en la categoría negro, y África Meridional donde se ubica a los catalogados como negros y como blancos descendientes de europeos. La jerarquización al interior de la población de África se realiza mediante la idea de raza ligada a los modos de vida. En la cúspide se sitúa a la categoría blanco, descendiente de europeos, seguida de la categoría blanco del norte de África, y en la base de la escala, se ubica a la categoría negro.

Africanos: África constituye otra categoría de alteridad del patrón de poder de la colonialidad. La representación de África se enuncia desde la perspectiva de los europeos, lo que se evidencia en los presupuestos del discurso eurocéntrico. Se hace una presentación negativa de África como el continente con menos desarrollo y con mayor retraso cultural, principalmente en los países ubicados en la zona ecuatorial.

La representación de la población se organiza como un discurso de apariencia racional, que muestra estadísticas comparadas como pruebas irrefutables del atraso y subdesarrollo de África, desplazando al campo más neutral de la ciencia los ámbitos políticos de las relaciones sociales. El modelo demográfico se marca como crecimiento demográfico moderado 
porque si bien las tasas de mortalidad infantil se cuantifican como altas, hay una baja esperanza de vida, entre los 40 y 50 años. Se coloca énfasis en las condiciones de vida extremas de la población, cuantificando la tasa de mortalidad y el crecimiento demográfico como muy altos, en contraste no sólo con los países desarrollados sino con los subdesarrollados.

La densidad de población se cuantifica como baja. Las causas de esta densidad se atribuyen a las condiciones ambientales por el clima inadecuado de los hábitats de desierto, estepas y selvas, y la pobreza de los suelos; a la población por las luchas entre las tribus, a la práctica de la agricultura con bajos requerimientos energéticos externos que se equipara con el atraso al considerarles como tradicionales, rudimentarias y de bajos rendimientos, a las condiciones de salud, a la elevada tasa de mortalidad infantil, a las enfermedades endémicas, a la falta de higiene y a las creencias religiosas. También se mencionan las consecuencias del colonialismo y los prejuicios raciales que han ocasionado el exterminio de grupos poblacionales.

La población es caracterizada por el predominio de lo rural con actividades económicas en el sector primario, en oposición a lo urbano. Las ciudades, señas que indican la ruta progresiva hacia la modernización, en el norte se adjudica su fundación a los europeos, en el sur se relacionan con la presencia de la categoría blanco descendiente de europeo. El nivel cultural de la población se evalúa como el más bajo de todos los continentes. Para que no haya dudas de tan bajo nivel, se incluye información detallada acompañada de pruebas numéricas, que dan cuenta de los grandes contrastes con el modelo de europeo culto: analfabetismo cuantificado en un $92 \%$, pocas universidades, establecimientos mal dotadas, ausencia de ciencia, bajo índice de radioescuchas, escasos periódicos, bibliotecas, museos y casas de la cultura. Se argumenta que la causa de los problemas culturales es la falta recursos económicos, humanos y técnicos ${ }^{27}$.

El subdesarrollo se atribuye especialmente a factores internos de la sociedad y de su territorio: condiciones de la geografía, el aislamiento de la civilización y la población. Entre los factores externos se mencionan el colonialismo y el racismo. Con la variable geográfica se explica el

${ }^{27}$ DE MORENO y ORTIZ. (1983): óp., cit, pp. 136-137. 
subdesarrollo como una consecuencia de límites naturales y ecológicos: geomorfología de las costas que carecen de accidentes lo que no posibilita la construcción de puertos y el acceso a los mismos, ríos con poca navegabilidad, ecosistemas de selva y desierto inadecuados para construir vías de comunicación y el clima extremo del desierto. Además, se aduce que la mayor proporción de África se encuentra en la zona ecuatorial. En el determinismo geográfico esta zona corresponde a la menos apta para el desarrollo, ideología que traslada a la geografía, las diferencias de poder social.

El criterio del aislamiento de la civilización alega que el atraso de las poblaciones periféricas al centro de poder, se debe al aislamiento de la civilización, mientras que el contacto con ellas conlleva necesariamente al progreso para quienes la padecen. Este argumento se enmarca dentro de la función de legitimación de la expansión de las sociedades poderosas, oculta que la dominación produce explotación de la gente y de sus territorios, a causa de la dependencia estructural generada en dicha relación. En la siguiente cita en primer lugar, se aduce que África es atrasada pese a la presencia de civilizaciones antiguas en la zona norte y, a que su descubrimiento por parte de los europeos, se hizo en la misma época que América, circunstancias que debieron haber influido en un mayor desarrollo. En segundo lugar, se clasifica a la zona septentrional de África como más desarrollada por el contacto con los pueblos del mediterráneo, mientras que la zona ecuatorial aparece como inculta, primitiva y sin desarrollo por efecto del aislamiento:

El aislamiento: Si el África del norte se civilizó desde los primeros tiempos, ello se debió al contacto con los pueblos del Mediterráneo; en cambio, el resto del continente, aislado durante siglos de la otra parte del mundo, ya por un inmenso desierto, el Sabara, ya por los océanos que durante mucho tiempo nadie navegó, permaneció inculto, primitivo y sin desarrollo económico.

El criterio de la población considera los conflictos entre grupos étnicos y atribuye a la gente características que le mantienen en un estado de atraso y subdesarrollo. Por una parte, se manifiesta que se trata de

\footnotetext{
${ }^{28}$ PARRA. (1978): óp., cit, p. 207.
} 
una subestimación de la raza negra, que desde afuera sólo se ha visto como mano de obra resistente para los trabajos duros. Por otra parte, a la gente se le adjudican cualidades particulares que la muestran con una especie de incapacidad mental para asumir la modernidad, como ser ignorantes, analfabetos, incivilizados y, carecer de mano de obra calificada, hábil y experimentada para la agricultura abanderada por la ciencia y la industrialización.

El colonialismo también se menciona como causante del subdesarrollo de la población de África y, en uno de los manuales también se señala al racismo. Marañón y otros hacen una presentación detallada y crítica del colonialismo y el racismo como causa del subdesarrollo. Al contrario de la perspectiva asumida por Arbeláez ${ }^{30}$, que glorifica la colonización como una gran hazaña iniciada por las expediciones de audaces exploradores que revelaron la riqueza vegetal y mineral de África, convirtiendo al continente en una economía de plantación y de grandes zonas exportadoras, gracias a la mano de obra barata de la población. Los europeos suelen aparecen directamente como agentes responsables del colonialismo y el neocolonialismo. Se menciona el control político y la dependencia económica, la apropiación y explotación de la gran cantidad de recursos minerales de África, por parte de compañías europeas y norteamericanas, así como los pocos beneficios para la población del continente y, la reducción de África a una zona de explotación de materias primas y plantaciones para la exportación hacia las potencias extranjeras.

En resumen, África opera como una categoría de alteridad del discurso eurocéntrico manifiesto en los manuales escolares de geografía. El significado alude al subdesarrollo y atraso cultural, a través de atribuir características negativas a su territorio y a su población. Si bien, también se reconoce que el colonialismo es una de las causas del subdesarrollo.

Áfricas: La población de África se representa perteneciendo a tres razas: negra, blanca y amarilla, con predominio de la primera, seguida de la blanca y por último la raza amarilla. El continente se divide en tres regiones que en términos generales se asocia con el

\footnotetext{
${ }_{30}^{29}$ MARAÑÓN y otros. (1984): óp., cit, pp. 174-176.

ARBELÁEZ. (1976): óp., cit, p. 140.
} 
predominio de determinado grupo racial: África Septentrional, África Central o Tropical y África Meridional.

La población etiquetada como amarilla es invisibilizada, la población categorizada como blanca y negra se subdivide en grupos. La categoría blanco se clasifica entre los que habitan África Septentrional, de origen árabe, judío, bereberes y del sur de Europa, y los descendientes de europeos (holandeses, británicos), especialmente en el sur. La categoría blanco del sur se describe positivamente en cuanto al estilo de vida, que se considera cercano al europeo por la agricultura intensiva, las ciudades, la industria, la inversión de capital y la técnica europea, además de contar con un clima de estaciones. Se valora como la zona de mayor desarrollo de África. No obstante, se hace una presentación negativa y crítica del apartheid, también nombrado como segregación racial y a veces como racismo. Van Dijk ha encontrado que una de las características típicas del discurso racista es que niega o atenúa el racismo en los territorios más cercanos del nosotros, a la vez que se condena y se habla explícitamente del racismo en tiempos y lugares más lejanos, en este caso, Sudáfrica. Arbeláez expresa que el blanco (se asocia sólo con afrikáners salvando a los ingleses), aparece como responsable directo de la segregación racial en Sudáfrica: sujeto que proclama la superioridad blanca frente al resto de la gente, etiquetada como negro, asiático o mestizo; que controla la económica relegando a los no blancos a los peores empleos y las bajas remuneraciones, que impide la capacitación de los no blancos como obreros calificados, que produce el segregacionismo en el transporte, las escuelas y el lugar de residencia, que concentra las posiciones políticas y las tierras.

La categoría blanco con referencia al norte de África se subdivide en grupos con estilos de vida diferenciados en torno a la distancia con la modernidad. Se menciona el vínculo histórico con la civilización egipcia, la cartaginesa y la presencia del imperio romano. Los estilos de vida más cercanos a la modernidad, como las ciudades, se atribuyen al influjo de los europeos, mientras que los modos de vida por fuera de la sociedad industrial y urbana, se identifican como tradicionales, seña que marca su inferioridad. Los pueblos al contar con población

${ }^{31}$ VAN DIJK, Teun. (2009): "Racismo, discurso y libros de texto" http://www. iaeu.es / etextos / contenidos. php?id_texto $=7 \&$ urlorigen $=$ YXV0b3Jlcy5waHA/ cGFnaW5hPTY=

ARBELÁEZ. (1976): óp., cit, p. 154. 
sedentaria, se consideran cultivadores y civilizados. En los oasis la población es sedentaria pero pobre. Los pastores nómadas se califican como tradicionales: se describe su vida en relación con los animales y la vivienda en trashumancia. Los bereberes son caracterizados como pobres, y más tradicionales en el vestido, la comida y la vivienda, no por opción propia, ni por las condiciones históricas, sociales y ambientales particulares, sino por la lejanía de la influencia de los europeos.

Se hace una representación negativa de la gente enmarcada en la categoría negro. Las culturas de las poblaciones categorizadas como negro aparecen aisladas de aquellas categorizadas como blancas tanto del norte de África como de Europa, hasta la llegada de los europeos en el siglo XV. La categoría negro aparece conformada por diferentes grupos a quienes se nombra a través de etnónimos. Las poblaciones se clasifican de acuerdo con los estilos de vida como indicadores de atraso de la civilización. Los agricultores y ganaderos, se consideran un poco más civilizados que los cazadores recolectores (no se define como una mayor civilización sino como una menor incivilización). Se descalifican los sistemas agrícolas de pequeñas fincas de autoconsumo, al vincularles con la baja producción, las técnicas rudimentarias, la dependencia de las condiciones climáticas y las hambrunas, en contraste de la tumba de la selva para la gran producción de monocultivos realizada por los europeos. La agricultura de tumba y quema en las sabanas se valora como rudimentaria. Las aldeas se describen con el trabajo colectivo al son de canciones, y con viviendas toscas construidas con materiales naturales como la arcilla en las paredes y la paja en los techos. Los pastores, comparados con el modelo europeo, se asocian con una ganadería vacuna poco productiva porque únicamente se usa la leche y con bajo precio, porque no sirve para tiro y está expuesta a las epidemias. Los recolectores y cazadores, nómadas y seminómadas son situados en la menor escala de clasificación:

En Africa búmeda, dominan los negros: recolectores $y$ cazadores primitivos en las selvas $y$ cultivadores rudimentarios en las sabanas. (...). En las selvas habitan nómadas y seminómadas: pigmeos, bantúes, bosquimanos $y$ hotentotes. En las sabanas se practican cultivos sobre quemas. Los negros de estas regiones búmedas son menos 
Europeos y no Europeos en Manuales Escolares de Geografía Universal, Colombia 1970-1990

incivilizados que los primitivos de las selvas. Las aldeas, aunque son viviendas toscas, con paredes de arcilla y techos de paja, generalmente cónicas, son más confortables que las de los bantúes. En ellas el trabajo está organizado y se lleva a cabo en forma colectiva al son de canciones. (...). En las zonas más secas de la sabana hay ganado. Se crían bueyes, vacas, carneros y sobre todo cebuies. Pero este ganado es de escaso valor pues no son fuertes para el tiro, o las epidemias los exterminan. Lo unico que se aprovecha de ellos es la leche, ya que sus propietarios rara vez. los matan para utilizar la carne.

Los Pigmeos, bosquimanos y hotentotes, se sitúan viviendo en un estado primitivo y con poca evolución cultural. Se les niega la contemporaneidad al ubicarles perteneciendo a otro período de tiempo, el pasado más remoto. Los hotentotes son identificados como pueblos muy atrasados que viven de la caza, los pigmeos se definen como una raza degenerada y los bosquimanos se califican como prehistóricos. Estas poblaciones se definen con contenidos que resaltan la diferencia biológica y cultural, hasta rozar los límites de lo conocido para trasladarlo a lo extraño y lo anormal. Entre las pocas características se mencionan la baja estatura, la esteatopigia de las mujeres y la práctica de las deformaciones corporales; Marañón y otros manifiestan de los pigmeos y los bosquimanos que "viven en estado primitivo alimentándose de raíces, reptiles, insectos y larvas de termitas (arroz de los bosquimanos). (...) [Los pigmeos] junto con los hotentotes y los bosquimanos son pueblos primitivos de origen desconocido".

La religión de la categoría negro se devalúa al compararla con el islamismo y cristianismo. En África se identifican tres religiones, el animismo, el islamismo y el cristianismo. El animismo se vincula con la categoría negro, entre los cazadores el totemismo y entre los agricultores el culto a la tierra y a los antepasados. El islamismo y el cristianismo se consideran religiones de amplia proyección, practicadas por la categoría blanco. En la siguiente cita obsérvese

\footnotetext{
${ }_{34}^{33}$ ARBELÁEZ. (1976): óp., cit, pp. 138-139.

${ }^{34}$ MARAÑÓN y otros. (1984): óp., cit, pp. 177, 179.
} 
que se hace una mejor presentación del cristianismo, seguida del islamismo y finalmente del animismo. Del cristianismo se expresa que era profesado antes de la invasión musulmana (naturalmente, sin ser obligados) y que se preservan numerosos núcleos gracias a la labor infatigable de los misioneros, sujetos modelo dispuestos al sacrificio. Del islamismo se dice que tiene el mayor número de practicantes, $\mathrm{y}$ que fue impuesto por los árabes en la conquista lo que hizo que se perdieran esos pueblos. El animismo se asocia con el fetichismo, como propios de pueblos primitivos:

Existen tres clases de religiones: el animismo, el islamismo y el cristianismo. El animismo y el fetichismo son practicados por la inmensa mayoría de los negros primitivos de las selvas y sabanas. El islamismo es la religión predominante entre los blancos. La impusieron los árabes cuando en el siglo VII y VIII conquistaron toda el África del norte y del oeste. El cristianismo era profesado antes de la invasión musulmana, en toda el área mediterránea. Egipto hasta el macizo etiópico. La conquista árabe hizo que se perdieran estos pueblos. Gracias a la infatigable labor de los misioneros existen boy numerosos núcleos católicos.

En resumen, el discurso sobre África se enmarca dentro de la ideología del desarrollo. La representación hegemónica presenta al continente como el de mayor subdesarrollo y atraso cultural. Su población es jerarquizada en blanco descendiente de europeo/ blanco árabe y bereber del norte / negro de la zona tropical. Al primero se le atribuye un modo de vida cercano al europeo, al segundo se le ubica en diferentes modos de vida, los urbanos con influencia europea se sitúan en la cima, más abajo se ubica a la gente calificada de tradicional. De la categoría negro se genera una imagen negativa, se le define como perteneciente a los menores niveles de civilización.

\section{Oceanía}

La población de Oceanía se identifica con las categorías asiático, indígena y blanco. La categoría asiático se invisibiliza. La categoría indígena se nombra como indígenas, nativos o a través de gentilicios y etnónimos como maoríes o polinesios, micronesios, papúes o

\footnotetext{
${ }^{35}$ ARBELÁEZ. (1976): óp., cit, p. 137.
} 
melanesios. La categoría blanco se nombra como blancos de origen europeo, europeos, raza blanca o se alude a la ascendencia de los colonizadores: descendientes de los británicos, anglosajones, ingleses, irlandeses.

La categoría blanco de origen europeo se representa positivamente. Constituye el nosotros con el cual se identifican los autores del discurso expresado en los manuales escolares. Se le atribuye una mayor cantidad de población en Australia y Nueva Zelanda, en comparación con los indígenas. Se vincula con características como ser un pueblo vigoroso, deportivo, con costumbres británicas. Su nivel de vida se valora como alto, similar al de los países europeos que colonizaron el territorio, con buenas condiciones de vida, con alta cobertura en educación, salud y servicios sociales. El modelo demográfico se asemeja al de los países desarrollados, bajas tasas de natalidad y de mortalidad, con una mayoría de población urbana. Se sigue la idea según la cual, el contacto con los europeos al inicio no fue favorable para la gente porque trajo enfermedades y el alcoholismo y, diezmó a la población, pero, a cambio hoy la población ha crecido y tiene mejor nivel de vida como el de los europeos. Se valora positivamente que actualmente estos territorios estén poblados principalmente por la población blanca, que habla el idioma inglés, practica la religión cristiana y mantiene la cultura influenciada por Occidente.

El desarrollo cultural se valora positivamente en Australia, Nueva Zelanda y Nueva Guinea, por la presencia de museos, academias y universidades similares a las de Europa, y por el intercambio cultural con las metrópolis, a diferencia de los archipiélagos de Polinesia, Melanesia y Micronesia, considerados en un bajo desarrollo cultural que se equipara al neolítico "tiene uno de los índices de analfabetismo más altos del mundo, 95\%; el estado de primitivismo de los pobladores ubica sus culturas dentro de esquemas casi neolíticos" ". La cultura y costumbres occidentales se llenan con contenidos favorables como ser cómodas y acogedoras. Se valora positivamente la inmigración de la población blanca que se promueve como benéfica, mientras que la gente catalogada como negra y amarilla, se asocia con la mano de obra apta para los climas tropicales y se prefiere evitar su llegada ${ }^{37}$.

\footnotetext{
${ }_{37}^{36}$ DE MORENO y ORTIZ. (1983): óp., cit, p. 171.

ARBELÁEZ. (1976): óp., cit, p. 163.
} 
En contraste, la categoría indígena se representa negativamente. Se la tilda de primitiva, semisalvaje y semicivilizada. Para situarle en la alteridad, se resalta la diferencia cultural en el modo de vida, así, los melanesios son descritos por Parra mediante la poligamia, la vivienda en la copa de los árboles, el vestido (suelen ir desnudos y llevan a lo más cinturones y adornos, especialmente un abanico de plumas en la cabeza), los adornos corporales (Los papúes se perforan el tabique de la nariz y las orejas para colocarse narigueras o para llevar la pipa) y las relaciones de amistad (con el fin de honrar a sus amigos les entregan la cabeza para que los despiojen y se tomen sus parásitos como golosinas).

A los melanesios, Arbeláez les califica como los más atrasados de la tierra por usar vestidos elaborados con fibras vegetales, usar herramientas de piedra y de hueso animal, alimentarse de vegetales y aún más, les tilda de antropófagos incorregibles. A los polinesios se les describe como osados navegantes en piraguas frágiles, dedicados a la pesca y la cestería. Igualmente se hace una representación en la que se hace énfasis en la diferencia cultural. De esta manera, Parra describe detalles en lo concerniente con la división política (son poco tradicionalistas, pero sin embargo se dividen en clases sociales: nobles y plebeyos), las viviendas elaboradas con materiales de la naturaleza (Las casas son comunales y de grandes dimensiones, construidas de madera y cubiertas con hojas de palmera), el vestido con corteza vegetal y cuando usan telas resaltan el colorido (Confeccionan faldellines con la corteza del papiro, lo que en algunas partes es la única vestidura. En algunas islas es ya frecuente el uso de telas europeas de lino de color vistoso) y el adorno corporal (Son muy amigos del tatuaje, de adornos, collares y abalorios). La población de algunas islas del pacifico como Hawái, se describe como feliz y despreocupada, como objeto en escenarios propicios para el placer y la contemplación de los turistas.

La religión de la gente categorizada como indígena se define como pagana, animista, creencias heredadas de la época primitiva, que persisten pese a la influencia de las religiones cristiana y musulmana. Sus idiomas se devalúan al llamarles dialectos a diferencia de los idiomas de los países colonizadores llamados lenguas, excepto el maorí que a

${ }_{39}^{38}$ PARRA. (1978): óp., cit, p. 234.

${ }^{39}$ ARBELÁEZ. (1976): óp., cit, p. 160-161. 
veces se menciona el hecho de ser lengua oficial en Nueva Zelanda. Se los describe conservando las lenguas, las costumbres y la organización social calificadas como primitivas, dando la idea de que lo normal sería que ya las hubieran perdido, pues han vivido la aculturación occidental. La población de la categoría indígena se considera aislada y con poca población. La disminución de la población y la desaparición de pueblos, suele presentarse en forma general y como un proceso natural sin mencionar a la población de la categoría blanco como agente responsable. Así, en Rojas y Rodríguez se manifiesta que las poblaciones Maorí de Nueva Zelanda "Han ido disminuyendo notablemente y hoy día apenas sobrepasan los 200.000 habitantes", aunque, a veces como en la siguiente cita, se menciona la colonización europea como responsable de diezmar a la población, eso sí, primero se deja claro que se trata de una población bastante primitiva:

Australia: Su población indigena es poca pero bastante primitiva; la colonización europea ha diezmado a los nativos. Actualmente predominan entre sus pobladores los descendientes de los anglosajones, que se concentran en el este y sur del territorio. Nueva Zelanda: Sus primitivos pobladores los maories, de origen polinesio, fueron cediendo a la colonización europea británica; boy en dia, aquéllos, sólo representan el 7\% de su población y el $93 \%$ es de raza blanca, descendientes de británicos e irlandeses. Las $2 / 3$ partes de la población se concentran en la isla del norte.

La población de Oceanía aparece en el discurso de los manuales escolares con una representación polarizada entre la categoría blanco y la categoría indígena. Los blancos, colonizadores europeos, se representan predominando en cantidad en Australia y Nueva Zelanda, con los indicadores y niveles de vida de los países desarrollados, manteniendo el idioma, la religión y la cultura de los países europeos. Los indígenas se representan con poca población en Australia y Nueva Zelanda, como primitivos, semicivilizados, con cultura asociada al tiempo pasado, con religión pagana, con materiales de la naturaleza y manteniendo las tradiciones pese a la aculturación.

\footnotetext{
${ }_{41}^{40}$ PARRA. (1978): óp., cit, p. 234.

${ }^{41}$ ROJAS, Ruth y RODRÍGUEZ, Elsa. (1987-1988): Brújula: Geografía universal 8. Bogotá, Voluntad, p. 129.

ROJAS, Ruth y RODRÍGUEZ, Elsa. (1987-1988): Brújula: Geografía universal 8.

Bogotá, Voluntad, p. 129.
} 


\section{CONCLUSIÓN}

Se sugiere que los autores de los manuales escolares de geografía universal examinados, se valen de los principios del eurocentrismo identificados por Quijano ${ }^{43}$ para representar a la población: a). La clasificación de la gente mediante la idea de raza. Se identifica a Europa con la raza blanca, Asia con la raza amarilla, África con la raza negra, dando mayor valor al blanco europeo, seguido del descendiente de europeo. El blanco europeo se constituye en el nosotros, en oposición a los otros, delimitados en la categoría blanco con procedencia en otros continentes, amarillo, indígena y negro b). La representación de la población mediante categorías duales, en las cuales se genera una tendencia a la polarización semántica entre europeos y no Europeos por medio de la ideología de la modernidad, el desarrollo y la civilización, articulada a c). La concepción de civilización humana como una evolución que parte de un estado de naturaleza hasta llegar a Europa y, la reubicación temporal de las diferencias culturales no europeas como el pasado de la trayectoria histórica que culmina en Europa. A los no Europeos se les vincula con el tiempo pasado al presentar a su gente y su cultura como estable, producto del pasado, sin cambios en el tiempo, asociándola con la costumbre, la religión y la tradición, con términos como hombres primitivos, prehistóricos y del neolítico.

El discurso hace una distinción de la población entre nosotros europeos, modernos, guiados por la razón, la técnica y la ciencia, que nos permite modificar la naturaleza en beneficio propio, y ellos, tradicionales, gente que actúa mediada por la tradición y la religión. Nosotros civilizados y ellos primitivos; Europa aparece como naturalmente civilizada, Asia como una civilización antigua que se estancó y África sin civilización; entre la población, los civilizados son los europeos y los primitivos son los grupos étnicos menos asimilados al mundo moderno colonial. Se maneja la idea según la cual, sólo en Europa se produce la civilización, de ahí es llevada por la categoría blanco al resto del planeta. La civilización de otra población se asocia con el contacto de Europa a través de los colonizadores, mientras que

${ }^{43}$ QUIJANO. (2003): óp., cit, p. 78. 
el aislamiento de Europa produciría la no civilización. El blanco lleva la civilización pese a la oposición de la religión y la tradición en Asia, que se convierten en obstáculos. Igualmente, Europa aparece como el lugar de llegada de la modernidad, la meta a la cual deben llegar todas las poblaciones tras europeizarse, la no modernización, a pesar de la influencia de los europeos no cuestiona el modelo, se lee como resistencia a la modernidad causada por la tradición, la religión y la diversidad cultural de las naciones.

\section{FUENTES}

ARBELÁEZ, Federico. (1976): Geografía universal 3: Asia, Europa, África, Oceanía, Regiones polares. Bogotá, Norma.

CAMACHO Mariela; MEJÍA Bolívar; MENDOZA Humberto. (1975): Geografía 3. Bogotá, Voluntad.

DE MORENO, Elsa y ORTIZ, Luis. (1983): Geocosmos: octavo grado del nivel básico secundario. Medellín, Susaeta ediciones.

MARAÑÓN Mortiner; GÓMEZ Hilda; VEGA Alcira; LÓPEZ Gilma; PRADA Cora. (1984): Geografía Universal 3. Bogotá, Norma.

PARRA, Juan. (1978): Geografía Universal, 3 curso de enseñanza media. Medellín, Bedout.

ROJAS, Ruth y RODRÍGUEZ, Elsa. (1987-1988): Bríjula: Geografía universal 8. Bogotá, Voluntad.

\section{REFERENCIAS}

ARREDONDO, María Adelina. (2003): "Desplazando al Rey en la escuela de la nueva nación mexicana: el Catecismo de República", en Historia de la Educación. N. 22. Salamanca, Universidad de Salamanca.

CHOPPIN, Alain. (2000): "Pasado y presente de los textos escolares", en La cultura escolar de Europa. Tendencias históricas emergentes. RUIZ, J. Madrid, biblioteca nueva.

HERRERA, Martha; PINILLA, Alexis; SUAZA, Luz. (2003): La identidad nacional en los textos escolares de ciencias sociales. Colombia 1900-1950. Bogotá, Universidad Pedagógica Nacional. 
JOHNSEN, Egil Borre. (1996): Libros de texto en el calidoscopio. Estudio crítico de la literatura y la investigación sobre los textos escolares. Barcelona, Pomares.

LO RUSSO, Cecilia Alicia. (2009): "La visión de los pueblos de Asia y África en los manuales de historia", en Íber. Didáctica de las ciencias sociales, geografía e historia. No. 61. España.

MENA, María Isabel (2006): "La historia de las personas afrocolombianas a partir de las ilustraciones contenidas en los textos de ciencias sociales para la educación básica", en Enunciación. No11. Bogotá, Universidad Distrital.

MORALES, Oscar y LISCHINSKY Alon. (2008): “Discriminación a través de las ilustraciones de libros de texto de Enseñanza Secundaria Obligatoria en España”, en Discurso \& Sociedad. N. 2.

QUIJANO, Aníbal. (2000): "Colonialidad y Clasificación Social”, en Journal of World Systems Research. N. 6 (2). Special Issue. Festschrift for Immanuel Wallerstein - Part 1.

QUIJANO, Aníbal. (2003): "Colonialidad del poder, eurocentrismo y América Latina", en La colonialidad del saber: eurocentrismo y ciencias sociales. Perspectivas latinoamericanas. E. Lander (Comp.). Buenos Aires, Clacso.

SOLER, Sandra. (2008): "Pensar la relación, análisis crítico del discurso y educación. El caso de la representación de indígenas y afro descendientes en los manuales escolares de ciencias sociales en Colombia", en Discurso \& sociedad. N. 2.

VAN DIJK, Teun. (2008): Ideología y discurso. Barcelona, Ariel.

VAN DIJK, Teun. (2009): "Racismo, discurso y libros de texto" http:// www.iaeu.es / etextos $/$ contenidos.php?id_texto $=7 \&$ urlorign $=Y X V 0 b$ 3Jlcy5waHA/cGFnaW5hPTY=

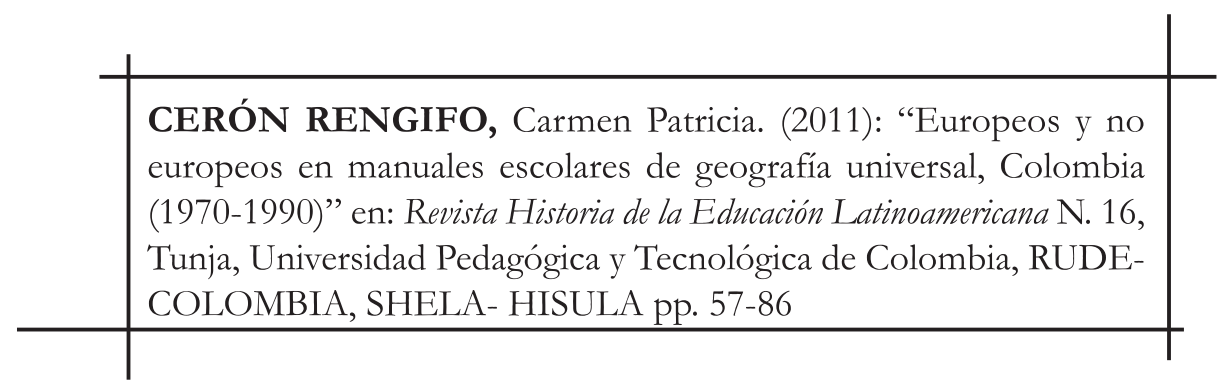

